\title{
Tissue Donor Eligibility
}

National Cancer Institute

\section{Source}

National Cancer Institute. Tissue Donor Eligibility. NCI Thesaurus. Code C159526.

Determination that potential adult or cord blood donor does or does not possess risk factors for relevant communicable diseases (as defined by the FDA) and identified through screening, testing, physical evidence, and review of readily available relevant medical records. 